Policing as a Performing Art? - The Contradictory Nature of Contemporary Police

\title{
Performance Management
}

\section{Accepted for publication by Criminology and Criminal Justice}

\author{
Authors: \\ Professor Jacques de Maillard \\ University of Versailles-CESDIP \\ Immeuble Edison \\ 43 Boulevard Vauban \\ 78280 Guyancourt
}

Jacques de Maillard is Profess or of Political Science at the University of Versailles-SaintQuentin, deputy-director of the Cesdip (a research centre affiliated to the CNRS, the University of Versailles, the University of Cergy and the ministry of Justice)

\author{
Professor Stephen P. Savage (Corresponding Author) \\ Institute of Criminal Justice Studies \\ University of Portsmouth \\ Museum Road \\ Portsmouth PO1 2QQ \\ Fax: 02392843971 \\ E-Mail: steve.savage@port.ac.uk
}

Stephen Savage is Professor of Criminology and founding Director of the Institute of Criminal Justice Studies, University of Portsmouth.

Word Count: 8,288 


\title{
Policing as a Performing Art? The Contradictory Nature of Contemporary Police Performance Management
}

\begin{abstract}
Performance management in criminal justice organisations has become a prominent issue in many countries and has faced increasing criticisms by scholars and practitioners. In this regard it is important to examine empirically how performance frameworks work concretely. We do so through the empirical examination of "performance regimes", i.e. the sets of performance indicators, internal procedures, instruments and processes of internal accountability through which performance is defined, assessed and monitored work in police organisations. By using the categories of traditional (target-based, top-down and short-term) and advanced (processes, more deliberative and creative and long-term) performance regimes, we have charted a process of evolution illustrated by the experience of two police forces in England. We argue that police performance management is a contradictory and hybrid process containing elements of both traditional and advanced regimes and in constant flux between them. Problem-solving and a focus on the quality of processes coexist with cascading pressures, an emphasis on numerical targets and other features of more traditional regimes.
\end{abstract}

Key words: Policing; Performance Management; Police Culture

This research was supported funded by the Agence Nationale de la Recherche - Grant reference: REFMANPOL] 


\section{Introduction}

It is widely recognised that criminal justice organisations across the world are steered, monitored and assessed through a more or less complex variety of performance indicators reflecting three broad forces: political pressures to reduce crime and deliver economies; neo-managerial thinking favouring the detailed measurement of performance; and technological change facilitating the retrieval of data relating to performance. More specifically regarding policing, much has been written about the consequences of performance mea surement and management, and in particular the impact of the pursuit of quantitative indicators of, and targets for, police performance on police actions and decision-making. In that respect four forms of consequences, essentially negative, have been identified. First, policing becomes overly focused on measurable activities, such as criminal detections, rather than other forms of problem-solving which may have no directly measurable outcomes but which are nevertheless socially beneficial, such as 'partnership policing' (for England and Wales, Crawford et al. 2005; Hough 2007; Cockcroft and Beatie 2009; Loveday 2006; de Maillard and Savage 2012; for Australia, Fleming and Scott 2008). Second, the pursuit of standardised and uniform performance indicators for policing has been associated with the rigidities of the centralization of policing through 'topdown' performance governance frameworks (for England and Wales, Fitzgerald et al. 2002; Loveday 2006; de Maillard and Savage 2012; for the US, Eterno and Silverman 2012; Sparrow, 2015). Third, performance management has reinforced a culture of cynicism within police organisations ('ticking boxes'), increasing the 
divide between managers and frontline officers (Fitzgerald et al., 2002). Fourth, pressures to demonstrate achievement of performance can lead to 'juggling' practices, such as the tactical under-recording of crimes, thus challenging police integrity (see Patrick 2011, for Britain; Matelly and Mouhanna 2007, for France; Eterno and Silverman 2012, Sparrow, 2015, for the United States).

Interestingly, these criticisms have not been confined to the academic world. In England (which will be the focus of this article), police chiefs, police representative bodies and politicians have also raised concerns about the directions which police performance management has been going, particularly in so far as they relate to a rigid and nationally-led performance framework. This critical dynamic, initiated by the Labour administration with the promise to dismantle all targets except those relating to public confidence in the police in 2008 (McLaughlin and Fleming, 2012), culminated in the removal of national targets altogether by the Coalition government at the beginning of the $2010^{\prime} \mathrm{s}^{1}$. Moreover, criticisms of narrow definitions of police performance based on 'crude' indicators (such as crime and detection rates) have led to the adoption of more sophisticated approaches of performance management based on a broader range of indicators (process and outcomes), a better quality of data and a deeper reliance on more sophisticated

\footnotetext{
1 The Conservative (then Coalition) Home Secretary Theresa May abolished all at least of Government targets for policing back in 2010 (The Independent, 29th June 2010). However, this was not to mean that pressures on police performance were to evaporate - on the contrary. The Policing and Social Responsibility Act 2011, under the banner of 'localism', introduced 'Police and Crime Commissioners' (PCCs), elected individuals who would, amongst other things, call chief officers 'to account' for their performance (see later).
} 
evidence (Neyroud, 2008). The College of Policing, for instance, a professional body created in 2011, has sought to develop and diffuse within the English police an evidence-based approach to policing. Virtually all police forces have responded in some form to this agenda; the Metropolitan Police Service for instance has introduced an Evidence-Based Policing program recommending the "use of evidence to inform better and more efficient policing in London" (Stanko, 2012, p. 4). These potential changes trigger an obvious question which is at the core of this paper: have the shifts in political orientation to police performance and the greater sophistication of performance approaches led in turn to the rise of a more advanced police performance model in English police forces?

Following reflection on the notion of a 'police performance regime' and the methodology of the research (1.), the paper proceeds to examine the association between police performance management (PPM) and the three dimensions of performance regime that can analytically distinguished: 'policing by numbers' (2.), the translation downwards through the police hierarchy (3.) and the temporal horizon of police activities (4.). What emerges is a picture of PPM as uneven, both within and between police organisations, as ambivalent and, in a number of respects, as fundamentally contradictory. 


\section{Analysing regimes of police performance using qualitative methodology}

\subsection{Traditional and advanced performance regimes}

Although the term 'regime' might imply unity and coherence, we use it to embrace varying mixes of norms, values, priorities and forms of knowledge and information (Edwards and Hughes 2012). Analysing performance regimes means examining sets of (more or less related) performance indicators, and the internal procedures, instruments and processes of internal accountability through which performance is defined, assessed and monitored. Police performance regimes can thus be defined in terms of the interplay between measures of police activity and how such measures are used through the various internal organisational processes to seek to produce particular organisational effects.

Police performance regimes may vary substantially. They vary significantly between nation states (de Maillard and Savage 2012) and vary over time within nation states; they can also vary between police organisations. To capture such variations, we can distinguish analytically between 'traditional' and 'advanced' models of police performance regimes.

'Traditional' police performance regimes, typical of performance management in the earlier stages of development of PPM, are characterised by:

- A framework which prioritises quantitative performance indicators and a central role given to target-setting; 'hitting targets' as an end in itself,

- Centrally driven organisational processes with a 'top-down' management style and the 'micro-management' of organisational units, 
- A short-term time frame with an emphasis on achieving targets within the performance reporting cycle (quarterly, monthly, etc.).

The perceived shortcomings of the 'traditional' regime, as seen above, seems to have been a driving factor behind the emergence of a more 'reflective' performance regime that we refer to as the 'advanced' police performance regime, characterised by:

- Systems of performance measurement with a greater focus on qualitative measures (without denying the significance and utility of quantitative measures as such) and with performance targets seen increasingly as a means to an end rather than an end in themselves, and a focus on solving the problems which differential performance levels expose,

- Greater flexibility and professional discretion granted to lower levels of the police organisation to seek and find solutions to performance differentials and shortfalls,

- A greater emphasis on long-term goals and increasing organisational effectiveness.

These analytical distinctions between traditional and advanced PPM regimes relate to ways of thinking and behaving, cultural interpretations held within police about which should be the priorities, and how performance should be measured.

To track potential changes of performance regimes, two dimensions, organisational and occupational, will be examined in the rest of this paper. The former refers to organisational processes: how low-level police supervisors 
(sergeants) and middle managers (from inspectors to chief superintendents) may through their activities and orientations impact on the internal diffusion of performance management. The latter relates to professional subculture: how do supervisors and middle managers understand and perceive performance management and use performance indicators?

\subsection{Methodological note}

This paper is based on data gathered from two contrasting police forces in England, the Metropolitan Police Service (MPS) with a predominantly urban population, the other a medium-sized 'county', or 'provincial', force with a mixed rural and urban geographical spread. We contend that findings from the study of the two forces can be generalised to policing nationally in England for two reasons. First that the MPS alone accounts for around one-fifth of police officers in the country. Second, that policing in Britain has become increasingly standardised due to the influence of Her Majesty's Inspectorate of Constabulary and police chief associations (Savage et al 2000).

Ideally, we would have wished not to identify either of our forces by name, but given the unique nature of the MPS it would have been obvious that which force it was. In each of two forces, the Police and Crime Commissioner and the MPS equivalent (the Mayor's Office for Policing and Crime) had decided to maintain performance regimes incorporating clearly stated targets (see House of Commons 2014: 15-18). Furthermore, in the case of the MPS, highly ambitious targets for local 
policing, captured by the slogan of the '20/20/20 Challenge', were set out (MOPAC 2012; Edwards and Prins, 2014): a 20\% reduction in 'key neighbourhood crimes', a $20 \%$ increase in public confidence in the police, and a $20 \%$ reduction in police expenditure (MOPAC 2012).

We conducted a total of 66 semi-structured interviews, 34 in the MPS and 32 in the provincial force. In each force, we focused on two territorial areas ('districts' within our provincial force, 'boroughs' within the MPS). The interview population was selected on the basis of purposive sampling and included the most senior officers responsible for performance in each force, area commanders responsible for force divisional performance units, and all ranks below that level through to constable. Most of our interviewees (54) were either middle managers or supervisors. The sample also covered a range of police functional units, including: safer neighbourhood teams; criminal investigation departments; first response/patrol teams; police staff with responsibilities for performance analysis; and interviewees from two police stations in each force. In the findings presented below, interviewees from the MPS are identified with the prefix ' $M$ ' and interviewees from the provincial force with ' $\mathrm{P}$ '.

Our interviews began by general questions on the content of the interviewee's work, their daily tasks, prior to discussing more specifically the practices and perceptions referring to performance issues: how are work priorities defined and how do these priorities impact on their work?; how is the interviewee's work assessed and, if they are in a managerial or supervisory position how do they 
evaluate the work of subordinates?; what kinds of tools are used to assess performance but also to record activity? Depending on the nature of the responses, we then asked questions around the existence of targets and extent of professional autonomy.

We chose semi-structured interviews as our primary research technique because of their capacity to obtain information on the perceptions, beliefs, professional identities and discourses of, in this case, police actors (Bryman, 2003). There are, of course, limitations to research of this kind: the information gained through interviews depends upon what the interviewee chooses to say or not to say, and on whether the individual concerned feels able to disclose what they might believe to be the case. In the context of the focus of our research, for example, police officers may seek to conceal certain practices, such as 'massaging' the figures and other various gaming practices, whilst conversely highlighting more 'noble' ones, such as more reflective and longer-term approaches to dealing with police performance data. As 'outsiders' in police research (Brown, 1996; Fielding, 1990) we were at risk of suffering the dilemma painted by Gary Marx, when he stated "much of the literature on controversial police topics breaks down into two categories: uncritical work by well-informed insiders, and critical work by uninformed outsiders" (1988, xiii). However, we contend that these concerns were at least largely mitigated by other factors. Firstly, in addition to interviews, we conducted a number of observational exercises (approximately 20 hours of observations in each force) of performance-related events, including force performance group meetings, daily 
management meetings and team briefings. Secondly, we were able to 'test' our findings with well-placed insiders with whom we established a close working relationship. Thirdly, we could to a certain extent cross check the information collected as we conducted around 15 interviews in each territorial area (see above). Furthermore, we were somewhat surprised by the candour of many of our interviewees who could hardly be accused of presenting a 'corporate' line!

Against this backcloth, we propose now to analyse the three dimensions of performance regimes mentioned above: numbers, hierarchy, and timing.

\section{Policing by numbers? Reds and greens for the thin blue line}

A recurring feature of our research is the centrality of numbers or data in the way middle managers and at a lesser degree supervisors define their activities, a centrality which induces contradictory orientations. More specifically, elements of the more traditional performance management regimes with their somewhat rigid and formulaic approach to the value of numbers sit alongside an alternative approach which is more oriented to a more reflexive use of numbers allied to problem-solving.

2.1. The centrality of figures for police middle-management: believers and sceptics

An overriding picture from our research is the centrality of 'working to numbers' within the daily routines of police middle managers. As in other sectors, 
police performance data is routinely presented in corporate dashboard form, with a colour-coded system of 'green, amber and red', flagging the degree of fit with set performance targets. Monthly, even weekly, data-based objectives were still routinely present within both forces. In the provincial force, one chief superintendent stated in relation to senior management that "they were more interested in your figures than your plan... They look at the greens, they look at the reds..." (P). A detective chief inspector describes walking into the office and, rather than exchange niceties with colleagues, his focus was on 'figures' and on what the computer reveals: "What is the priority? Computer. Oh! Red!" (P).

Comparison between units within forces and between forces themselves had become internalised: managers define their performance relative to others. For example, a borough commander described his earlier concerns about public confidence in policing in his borough: "It was the lowest in terms of victim satisfaction rates in London. The quarrel with that is we are at the bottom of England and Wales so it was a bad position to be in".

The prioritisation of such target numbers can of course lead to a narrow perspective on policing priorities. For example, a chief inspector of a Safer Neighbourhood Team bemoaned the focus on figures rather than on actual 'outcomes':

"A lot of times funding was specific around numbers, around positive or negative figures rather than positive or negative qualitative outcomes." (M) 
In a similar vein a detective chief inspector claimed that a focus only on crude numbers can distort decision-making:

"Sometimes you have senior police officers in particular with a uniform experience [who] have a limited knowledge of investigation, they are focused on the ' $n$ ' number... you can have a superior that doesn't understand what you do, they just see the reds and greens... and they criticise." (P)

This statement reveals a form of schism within police management over the legitimacy of 'policing by numbers'. There seems to be dissent among police middle managers and supervisors around the relevance of targets and more generally the use of performance indicators in the management of police units (Cockroft, 2012). The reliability and relevance of performance data for police action is a matter of contention. In this respect, the divide within police organisational culture is more nuanced than the classic differentiation between 'street' and 'management' cops (Reuss-Ianni 1983). Within management cops as such we would distinguish between 'believers' who see virtue in the 'healthy competition' which numbers and targets can create and the daily pressures this brings to improve performance, and 'sceptics' who are more guarded about what the pursuit of numerical targets can achieve.

Believers consider figures as reliable; to put it in the words of a detective sergeant who very regularly assessed his detectives, at the end of the day, "Stats speak for themselves" (M). On the contrary, sceptics would insist on the potentially misleading nature of figures and the dangers of reading them as straightforward signifiers of 'results'. Competition between police units on the basis of performance 
also provokes different opinions: believers consider that some degree of competition is always healthy in an organisation, whether between territorial areas, operational units or individual officers; sceptics are more concerned with the possible perverse effects of widespread use of comparison between units. Additionally, the effectiveness of police targets is contested: believers tend to consider that instituting performance targets holds the organisation together and furthers a sense of 'mission', whereas sceptics underline the possible distorting and resource intensive effects of targets. What is at issue here is almost a divide about what constitutes 'good police work': on the one hand the believers who see 'good police work' as the attainment of numerical results and on the other sceptics who differentiate such results from 'real' police work, or at least do not reduce good police work to numerical indicators alone. What this amounts to is in effect a 'mixed economy' of both traditional and advanced forms of police performance management.

\subsection{A mixed economy of performance regimes}

There appears to be a discernible and on-going shift within policing from a simple 'numbers game' to a more reflective problem-solving ethos, particularly in relation to uniformed policing functions, in which data is used not just for the purposes of target-setting but as intelligence to be used for proactive management. Our interviews reveal a strong sense that the police performance regime has evolved in ways that were more creative than performance regimes of the past; the performance culture is shifting to one more characteristic of what we referred to 
earlier as an advanced regime. The increasing focus on problem solving can mean that numbers are treated as signs of underlying processes rather than as significant in themselves. In the MPS, this is captured by a police performance (or 'business') analyst commenting on the direction of PPM:

"The direction is that it should be more about processes and not so much about numbers. So if a borough is not doing great in terms of numbers... that doesn't necessarily mean the performance is bad..." (M)

This means that judgements on the performance of policing units should involve an assessment of whether the processes attached to the numbers are appropriate or not. This entails a shift from the simple 'primacy of numbers' to one which treats numbers as signifiers of patterns and it is the significance of those patterns and solving problems they express which are becoming a more central concern. This problem-solving approach transforms performance data from being a totemic definition of what the police should aspire to, to being a source of intelligence for informed decision-making.

In turn this encourages a more intelligent use of data. In both forces middle managers talk positively about 'balanced scorecards', which involve linking different dimensions of performance to provide rich data for planning and decisionmaking. For instance, a superintendent links the use of this intelligence to new levels of support to his subordinates:

"We introduced balanced scorecards, it will look at how a team performed, at their outputs and inputs, it will usually include the attendance level, how many crimes 
they deal with, how many crimes they solved, and so on... When you had a team with a low arrest rate for a period of here of four months, the immediate reaction was 'what is going wrong? I am going to set them targets for some more arrests'... for me it was more, 'are you asking the right sort of questions?'... It could be because they were much more innovative in dealing with crimes, they could solve more crimes, while doing less arrests, because they were more innovative" (P)

In summary, if some components of the traditional performance regime are still doggedly alive within the police organisation, other features of PPM bey ond the simple 'working with numbers' are now part of the PPM landscape. This is consistent with Crawford's thesis that: "creative use of performance measurement... [can] encourage officers to value certain aspects of their work, such as encouraging crime prevention, problem solving and community engagement" (Crawford et al. 2005: 86; emphasis added). This potential creativity leads to the issue of managerial accountability.

\section{Translating targets downwards: the ambivalence of managerial}

\section{accountability}

One of the concerns of our research was with the ways in which targets for performance are translated, or not, as they are passed down the police hierarchy to the frontline - although we acknowledge that policing has always involved something of a struggle between management and the 'frontline' and never a simple 'top-down' process of transmission. We have explored this more within the context 
of police organisational/professional culture in another paper (de Maillard and Savage forthcoming). Here we were concerned with the extent to which performance targets set for the organisation are translated into the actions and behaviours of individual officers. Such a process is aptly described by Sparrow (2015: 29): “Adversarial managerial styles exercised at high levels within a department tend to trickle all the way down, resulting in intolerable pressure on frontline officers and, ultimately, inappropriate forms of police action on the streets". What we found was a more complicated picture: invasive accountability and cascading pressure exist but may be counterbalanced by internal processes.

\subsection{Invasive accountability for divisional commanders}

Like in Compstat (Willis et al. 2007), divisional commanders, typically at chief superintendent level (or in the MPS at Commander level) are at the fulcrum of the performance regime because they have to answer directly for the performance (or under-performance) of their geographical area to the chief officer team. In both forces monthly force level evaluation sessions (CrimeFighters in the MPS, Force Performance Meetings in the provincial force) were set up and the senior management team utilise dedicated performance analyst teams to drill down into data and present profiles to be used to increase performance in the organisation.

The Compstat programme, developed by the New York Police Department, was notorious for exposing police commanders to management review events where 'their' performance was subjected to hostile examination (Eterno and Silverman, 
2012; Moore 2003). In our research we did not find evidence of performance events of the intensity of Compstat regime; however, we did find that 'rituals of performance' (see Manning 2008; see also Manning 1997 for policing 'rituals') were a key part of contemporary police performance, whereby individuals are exposed to particular events at which the performance of themselves or relevant others is presented, examined, challenged and at which they are called to account.

An important dimension in this respect is the punitive nature of performance assessments: the theatre of performance operates at least in part by a ritual of symbolically punishing 'poor performers'. Commanders of 'poor performing' areas are asked to stand up and firstly explain why their figures were not 'good' and then go on to explain what they planned to do to improve performance. Performance rituals help create environments in which 'naming and shaming' processes can be set to work. These events are sometimes experienced by commanders as somewhat humiliating:

"You don't want to be the naughty boy... When we got worse [figures], I always remember that you felt like the class idiot... When they say that you don't know what are you doing, it was a horrible feeling." (Chief superintendent, P)

Divisional commanders are expected to know often specific details about what is happening in their division and be answerable for decisions made under their command, even decisions right down to the front-line. One divisional commander in the MPS expressed this in terms of his own 'accountability': "I feel the most accountable person to the performance in all the Met other than the Commissioner". 
The level of finely grained detail presented in the CrimeFighters meetings were resented as excessive by some commanders:

"I have to get my head round what my subordinates are doing in relation to those things because they ask for a level of detail which I don't think I necessarily need to know. I need to know things are happening but do I need the fine details of that?" (M)

These performance rituals were far more intense in the MPS than in the provincial force. In the MPS, divisional commanders never know fully what kind of questions they may receive from the senior officers, thus creating a form of permanent uncertainty:

"They pick on different bits each time and you go, 'what the hell is that?' and stuff you've not seen before... you are then given this thing and you think, 'where has this come from?' ..... figures that you don't recognise and then you have to do a lot of work trying to work out what it is, where it's come from and what they are looking for" (M).

Furthermore, the assistant commissioner (AC) in charge of local policing for the MPS did not hesitate to challenge divisional commanders. An inspector recalls a scenario widely shared within the MPS:

"You hear the story that a chief superintendent was being asked 'who does that for you?', 'oh inspector $x$ does it', so he [assistant commissioner] rings up inspector $x$ there in the meeting" (M).

Commanders could therefore be explicitly questioned on their internal management. For a period (it had changed over time as we shall make clear later), 
the style of leadership of the AC, who was from outside the Met and wanted to provoke, in his own words 'shock and awe', had been described as abrasive by some, brutal by others. In contrast, the performance rituals in the provincial force, such as the monthly performance meetings, were rather more gentle affairs, something apparent from our observations of such events. Chief superintendents can be seriously challenged but never to the degree seen in the MPS. One chief superintendent described the meetings as "not necessarily evil, but not helpful".

This places divisional commanders in an often invidious position: they are both part of the senior staff of the force accountable for all that happens under their command and a re often expected to know the detail of individual disposals of people arrested, charged, and so on. Not surprisingly, this can create a highly pressurised environment for those concerned. For example, we were told about one district commander who had "sleepless nights" before performance review meetings and even that his children were aware when such meetings were coming up because of his behaviour! Divisional commanders are at the helm of force 'business units' and where those units are the primary basis of intra-force performance comparisons it is they that are very much in the 'firing-line' within the performance regime, even if the pressure also goes down the line.

\subsection{Transmitting pressure}

We found clear evidence of what we would call the transmission of pressure from senior to front line levels of the organisation. This is where organisational 
performance targets are transmitted from senior management through to middle management and supervisors.

This cascading process may be translated through two quite varying routes. The first is the more formulaic definition and monitoring of numerical targets that are pushed down at every level of the organisation through to frontline officers. Targets set 'on high' are translated into specific actionable objectives for individual frontline officers, leaving little by way of officer discretion in those areas of police activity. For example, one detective chief inspector, one we would classify as very much a 'believer, explained how she sets quite specific action targets for her inspectors and sergeants and sees that those targets are then handed down to front line detectives, in order to help achieve targets for her force area. She also presents this in terms of generating 'healthy competition' within her team of detectives:

"I'll give everybody four objectives and they will give their detectives four objectives. One of those four objectives could be to detect four burglars per month but that doesn't seem a lot. When you have a low arrest rate around burglary, that's a lot, so it holds people to account... that does inject a little healthy competition." (M).

Some specific operations express perfectly this form of top-down management by numbers. For instance, the MPS has engaged in events given the name of 'Operation CUBO', where activity right across the force is targeted for a single day at a particular offence, such as uninsured car drivers, in this case involving widespread stops of vehicles and arrests to substantially boost performance in that area of policing. 'CUBO days' reflect what the chief officer had 
in a previous post has called 'Big Wing Days' (named after the World War II Battle of Britain) - large scale raids and arrests of particular groups of offenders. On these days, every borough has clear numerical targets and is expected to attain them with close monitoring by the senior hierarchy.

However, the setting of such individual targets for frontline officers is not the most frequent option. Both forces had largely abandoned specific targets for frontline officers (even if differences may be observed within units depending on the style of supervisors, see below). This is where the second route, more indirect and diffuse, takes place: here there is no clear obligation to attain individual targets, but an increased, recurring, questioning and challenging of decisions made by individual officers working on specific crimes, particularly volume crimes. This is notably the case in investigatory units and is illustrated by these comments from a detective sergeant about the pressures around detections for burglary and robbery offences:

"We are in a lot of pressure not to release people from custody that had been arrested for robbery and burglary without charging them... if that happens, we have to answer to the management team in the morning meeting. They want to know that because they look for the stats. And they go 'Hang on, Joe Bloggs was in for robbery yesterday, and he's released NFA [no further action]. Why was that? Why hasn't this robbery suspect been charged?'" (M)

In this case the intrusion of supervisors and middle managers into operational decision-making derives indirectly from performance targets: the officer is made 
accountable on a routine basis for his/her individual decisions, especially when they concern designated priority crimes. The process is therefore more indirect than the simple imposition of numerical targets down the line, and usually involves a scenario whereby, under pressure to attain targets, middle management reinforces its monitoring and challenging of the decision of subordinates. Through targets, monitoring procedures have been consolidated to form a tighter disciplinary framework.

Such a scenario leads to different reactions from police personnel. Whilst some, almost reluctantly, recognise what they feel are near-positive aspects of this intrusiveness, referring to an enhanced level of interest shown by managers in what is happening down the line of the police hierarchy, most officers express resentment about the new forms of accountability as being 'suffocating', 'unjustified micromanagement' and time consuming.

\subsection{Soaking up, negotiating pressure: another role of the middle hierarchy}

However, we would identify a number of qualifications to the straightforward 'top-down' performance scenario. Not all police managers and supervisors appear to take the position of simple 'transmitter' of performance pressures; some of them at least are prepared to act as a sort of 'buffer' for the pressures coming down the line. We found evidence that some middle managers and supervisors took a position where they would 'soak up' the pressure coming from above. Despite its rigidity, the performance framework leaves potential leeway 
for negotiation, interpretation and even forms of resistance within the police organisation. This may be seen at two levels: divisional commanders' relations with their superiors and supervisors' relations with frontline officers.

Divisional commanders have over time it would seem been given degrees of discretion over the definition of their local priorities. The extent of this depends largely upon the intensity of performance at the force level. In the MPS, performance meetings have become less 'brutal' over time. A borough commander for example compared the 'intimidatory' performance meetings of the recent past, where "you were keeping your head down hoping they won't ask you the question that you knew they should be asking you" to one "where such events are not quite as aggressive as it was." (M). This appears again to reflect a picture of performance regimes which ebb and flow between 'traditional' and more 'advanced' logics. Performance regimes are a moving target, not set in stone. This may create possibilities for levels of autonomy within the force, escaping the one 'size fits all' rationale. A chief superintendent expressed this relative capacity to adapt locally to the force objectives:

"Victim satisfaction is my first priority. It's what I give to my staff. SAC [serious acquisitive crime] is probably the force number one priority. Victim satisfaction, I consistently since I arrived here said, 'get your investigation right and everything else will follow through'. So, for me, it's victim satisfaction and commission rates, reducing crime... And then it's violence, sexual offences or whatever. So I interpret the force priorities into something that I believe people can sign up to and deliver on". 
However, this degree of managerial autonomy is limited and conditioned by having to present good 'results': the same chief superintendent also mentioned that he is assessed on the basis of six performance indicators (including crime rate, detection rate, the management of his team and value for money). He has to reach four out of six targets if he is not to be considered 'unsuccessful'. In other words, autonomy is conditioned by reaching targets, which may appear somewhat paradoxical!

Supervisors, normally sergeants, appear to have equivalent degrees of discretion. Performance management has prompted a new role for sergeants, by increasing that part of their work devoted to the monitoring of scoreboards and recording of their subordinates' activities. However, styles of supervisory management vary. Sergeants often manage different types of constraints: reaching targets, but also protecting officers; respecting instructions, but also taking into account operational discretion. Some, particularly more experienced sergeants, may absorb the pressure at their level, protecting their sub ordinates from the full blast of the performance regime and thus moderating the effects of downward performance pressures, unlike some of the counterparts, who are much more 'figures' oriented:

"That's just the way I work as well, if you spoke to [sergeant named]... it would all be about community work; she likes the community side whereas I like the investigative side... she's not worried about figures. She always moans at me because I'm worried about figures" (Police sergeant, P). 
In the MPS, two detective sergeants, while regularly assessing the individual activities and caseload of the detectives, practice this performance monitoring on different timeframes, one operating on a short-term basis, the other adopting a more distanced and long-term approach:

"Every month I run an inquiry on the crime reporting system, the CRIS system... An inquiry has been specifically created to look at performance, so I am able to tell who of my officers have got the most detections, the number of crimes they have investigated... And then at the end of the month, I will say to them, this is only compared with the evidence, it is a way of introducing competitiveness between the five... They may not like it but..."

"What I try to look for is trends because obviously, on a short term basis... Because the nature of our business changes so much on a daily basis. I mean, one day, you might get five burglaries. Another day might not be any. So you have to look at trends really, which is what I do and my team as well because I'll keep an eye on them on a daily basis... But I measure them, say, over three months or six months".

This leads us to consider the linkage between police performance and timeframes for police decision-making 


\section{Performance management: short-time and long-term approaches}

PPM situationally and paradoxically employs both short-termist 'solutions' and longer-term timeframes. Performance regimes at one and the same time demand both short-term returns and long-term improvements in the delivery of policing.

\subsection{Shortening the time horizon}

Terms such as 'quick wins', 'fire-fighting, and 'knee-jerk reactions' were used at various points by our interviewees to capture the short-term pressures that the police sometimes face under PPM. Under pressure to reach often politically sensitive targets (such as those for serious acquisitive crimes in the provincial force), senior management can at times issue edicts which require specific and short-term responses, time-limited targets and the like.

Short-term pressures are widespread. Some interviewees, particularly those attached to criminal investigation departments, refer to daily monitoring of performance. For example a detective inspector expresses it as follows:

"I'm aware of my numbers every day. Every day in the meeting they bring up on the screen the current performance on a daily basis. You are measured against the previous year's performance, so you are measured against the number of robberies whether they have gone up or down on last year... if you hit below or above that target and if they are increasing or decreasing so that's on a daily basis." (M)

A strong impetus in this respect comes from daily management meetings 
where recent events are reviewed and objectives recalled. On priority crimes, close monitoring of cases and follow-up of figures are typical. One chief inspector even mentioned hourly pressure, if crime 'spikes' appear:

"The pressure is almost hourly sometimes. We have performance meetings at 9.00 the locality, at 10.00 the area, 10.30 which the force. Every day, 7 days a week. Sometimes at the force level, you have some senior officers talking about low-level assaults. And that should be a strategic meeting". (M)

Linked to this, pressure on improving performance against targets can shift from one area of performance to another: what are priorities at one time are less so at another, and with that the pressures for short-term returns can grow and with them the period for performance review can be shortened. However, this tells only part of the story.

\subsection{Combining short-termism with more strategic problem solving}

Truncating timeframes can generate scepticism amongst police managers and supervisors who may be attached to a more nuanced conception of their role and activity. Whilst seemingly loyal to their own organisation, they seek to distance themselves from what they deem to be 'knee-jerk' reactions associated with some areas of PPM:

"What I have always resisted is a knee-jerk reaction on the basis of quite superficial information and data, something that I have tried to resist... At times, I would be in 
conflict with my organisation. ... but the instruction is 'Something has gone up, do something about it'. It has been my frustration". (Chief superintendent, P)

Yet even within this short-termist framework there may be some leeway for a more 'strategic' approach. Some managers put under pressure to return immediate performance results may be in a position where they can "buy some time". In such cases, they are able to negotiate with their hierarchy a degree of room for manoeuvre in order to decrease, or manage, the pressure:

"When I took over the district, we were bottom. I had quite a lot of pressure to do something about it. One of the first things I said, 'you have got to give a hundred days to get my head round'. I have never commanded a district before. It was one of the ways to keep them at bay. 'Give me three months and I will tell what the priorities are, and I will have a plan'". (Chief superintendent, P).

Such a statement draws attention both to the potential rigidity of the performance regime but also to the leeway that may exist within it. The same officer also mentioned the 'low hanging fruits' and 'easy wins', easy-to-reach targets that, when exploited, enabled him to 'buy time' and water down short-termist pressures.

This is related to an approach that holds it necessary to go behind and beyond the simple figures to assess underlying trends. A chief inspector compared this longer-term approach with the short-termism of the past:

"We have a performance meeting every week. We are getting pushed around, not 'why are figures have dropped?', and not looking at it from a week to week basis... but looking at the rolling twelve months and the current picture, and comparing the two 
together so that we understand the trend around it... asking questions around 'what is happening?', 'how much do we understand what the problem is'?" (M)

\section{Discussion and conclusion}

At a time when performance management in police organisations has become a prominent issue in various countries (de Maillard and Savage, 2012; Sparrow, 2015) and crude measures have come under increasing criticisms by scholars and practitioners alike, it is important to examine empirically how performance frameworks (what we call here performance regimes) work in police organisations. England offers a stimulating case-study as 'policing by targets', after having been favoured for two decades, came to be politically rejected at the end of the first decade of this century (see House of Commons 2014). By using the categories of traditional (target-based, top-down and short-term) and advanced regimes (processes, more deliberative and creative and long-term), we have charted a process of evolution illustrated by the experience of two forces.

Our overarching picture of police performance management is a contradictory framework containing elements of both traditional and advanced regimes and in constant flux between them. Problem-solving and a focus on the quality of processes (as opposed to simple numbers) coexist with cascading pressures, an emphasis on numerical targets and other features of more traditional regimes as outlined earlier. The performance regime ebbs and flows in intensity and direction. Our findings echo research on the co-implementation of community 
policing and Compstat in American police departments (Willis et al. 2010): although the doctrines underpinning these policing models are conceptually opposed, in terms of core policing mission and the status of organisational flexibility, and so on, police departments operate these activities in parallel with one another, generating tensions as a consequence.

We are therefore left with the question: why do strong features of the more traditional forms of police performance regime continue to survive, with its focus on working to numbers and short-termism, despite their widely recognised shortcomings? First, the withdrawal of central government commitment to targetsetting should not be seen as a relaxation of the police performance regime imposed by political actors as such, but rather a redrawing of the political framework governing police performance in which the axis is shifting from the centre to the local. This is most evident in the MPS, where an assertive local governance framework is firmly in place and which was very much steeped in an ethos of target-setting and rigorous performance monitoring of the police by local government. This explains, for example, why, despite the adoption of strong elements of the more 'advanced' performance regime at various levels of the force, there are still examples of quite openly short-termist policing decision-making governed by the concern to 'deliver on targets'. The shift from central to local political pressures on police performance is less evident in our provincial force, where, as has been stated, the Police and Crime Commissioner framework has been in place for a relatively short period of time. However, one dimension is of primary importance for the senior leadership 
team in the provincial force: performance in national league tables. This is clearly a driver, as a chief superintendent told us:

"We have had no targets for several years now. But, what is done by the Home Office is a league table... with each force, you are given a place and nobody wants to be in the relegation... Even if you haven't set any targets, our leaders have used this terminology, 'I want to be in the [top] 15 forces'" (P).

We should note here that 'league tables' as such are produced by Her Majesty's Inspectorate of Constabulary rather than the 'Home Office'. Nevertheless there is clearly a question for the future of PPM: will the new forms of local accountability (which the PCC model embodies in England and Wales) generate similar pressures for decision-making to be mechanically oriented to the attainment of targets (Reiner, 2013), or will they enable more reflexive performance systems which are based on a longer term problem-solving ethos? The question has clearly a broader reach, as performance indicators are a way of governing at 'a distance' by setting targets and facilitating audit. Would local political accountability favour a more advanced performance regime? Our research would point tentatively to the negative.

Second, intensive PPM is not just something imposed from without: police managers possess agency and, as we have argued, some middle managers can be seen as 'believers' in the apparent benefits of the 'healthy competition' that comes with the 'naming and shaming' process. This is hardly surprising as a whole generation of senior and middle-ranking police officers have been raised (if not 
immersed) in a professional environment in which the 'performance culture' is taken as part and parcel of policing in the contemporary era. This relates for us to what might be called the self-imposed dimensions of police performance regimes - the extent to which the police orient their behaviours to target-based performance even when it is not required of them by others external to the organization. 'Believers' are more inclined towards standardised procedures, hierarchical structures of authority, target-setting and routine and regular performance review, which resembles the organisational professionalism analysed by Evetts (2006). Far from seeing target culture as distorting of real policing, many senior police managers have held it to be essential to the policing function.

Conversely, we have argued that many middle managers and supervisors adopt more critical stances towards police performance regimes that are seen to be time consuming, too 'top-down' and too numbers-focused. This interplay between 'believers' and 'sceptics' creates an interesting cultural dynamic for the workings of PPM and the police service more generally. With regards to the debate on a 'new professionalism' in policing (Fyfe 2013) and the notion of a policing profession associated with reflexivity and evidence-based decision-making - one more comfortable arguably with advanced performance regimes - we would argue that both external and internal forces play to ensure that elements of traditional performance regimes will continue to survive and ensure that police performance management will in turn embody contradictory forces. 


\section{References}

Brown, J. (1996) 'Police research: some critical issues' in Leishman, F.,

Loveday, B. and Savage, S. (eds) Core Issues in Policing, London: Longman

Bryman, A. (2003), Research Methods and Organisational Studies, London:

Routledge

Cockroft, T. (2012), Police culture: themes and concepts, Abington: Routledge.

Cockroft, T. and Beatie, I. (2009), 'Shifting cultures: managerialism and the rise of "performance", Policing: An International Journal of Police Strategies $\mathcal{E}$ Management, 32(3): 526-540.

Crawford A., Lister S., Blackburn S., Burnett J. (2005), Plural Policing: The Mixed Economy of Visible Patrols in England and Wales, Bristol: Policy Press.

Edwards, A. and Hughes, G. (2012), 'Public safety regimes: negotiated orders and political analysis in criminology', Criminology and Criminal Justice, 10 (3): 260283. 
Edwards, A. and Prins, R. (2014), 'Policing and crime in contemporary London: a developmental agenda', European Journal of Policing Studies, 2 (1): 403-435.

Eterno J. and Silverman, E. (2012), The Crime Numbers Game: Management by Manipulation, New York: CRC Press.

Evetts, J. (2006), 'Short note: the sociology of professional groups: new directions', Current Sociology, 54(1): 133-143.

Fielding, N. (1990), 'Mediating the message: affinity and hostility in researching sensitive topics' American Behavioural Scientist 33 (5): 608-620

Fitzgerald, M., Hough, M., Joseph, I., Qureshi, T. (2002), Policing for London, Cullompton: Willan.

Fleming. J., Scott, A. (2008), “Performance management in Australian police organisations", Policing, 2 (3): 322-330.

Fyfe, N. (2013), ‘Complex transition and uncertain trajectories. Reflections on recent developments in police professionalism', Journal of Workplace Learning, 25 (6): 407-420.

Hough, M. (2007), 'Policing, New public management and legitimacy in Britain', in T. Tyler (ed.), Legitimacy and criminal justice: an international perspective, London: The Russell Sage Foundation.

House of Commons (Home Affairs Committee) (2014), Police and Crime Commissioners: progress to date, London: The Stationery Office Limited. 
Loveday, B. (2006), 'Policing performance: the impact of performance measures and targets on police forces in England and Wales ', International Journal of Police Science E Management, 8 (4): 282-293.

de Maillard, J. and Savage, S. (2012) 'Comparing performance: the development of police performance management in France and Britain', Policing and Society, 22 (4): 363-383

de Maillard, J. and Savage, S. (forthcoming) 'Les détectives dans la cage de fer néo-managériale ? Une analyse de deux polices anglaises' Sociologie du Travail Manning, P.K. (1997), Police Work: The Social Organisation of Policing, Long Grove Il: Waveland Press

Manning, P. K. (2008), 'Performance rituals', Policing, 2(3): 284-293.

Marx, G. (1988), Undercover. Police surveillance in America, Berkeley, University of California Press.

Matelly, J.-H. and Mouhanna, C. (2007), Police: des chiffres et des doutes, Paris: Michalon.

McLaughlin, E., Fleming, J., 2012. 'Through a different lens: researching the rise and fall of New Labour's public confidence agenda', Policing and Society, 22(3), 280-294.

MOPAC (2012), Police and Crime Plan 2013-2016 London: Mayor's Office for Police and Crime

Moore, M. (2003), 'Sizing up Compstat: an important administrative innovation in policing ', Criminology and Public Policy, 2 (3): 469-494. 
Neyroud, P. (2008), 'Past, present and future performance: lessons and prospects for the measurement of police performance', Policing, 2 (3): 340-348.

Patrick, R. (2011), " Reading tea leaves": An assessment of the reliability of police recorded crime statistics', The Police Journal, 84(1): 47-67.

Reiner, R. (2013), 'Who governs? Democracy, plutocracy, science and prophecy in policing', Criminology and Criminal Justice, 13 (2): 161-180.

Reuss-Ianni, E. (1983), Two cultures of policing: street cops and management cops, New York: Transaction Publishers.

Savage, S., Charman,S., and Cope, S. (2000) Policing and the Power of Persuasion: The Changing Role of the Association of Chief Police Officers London: Blackstone

Sparrow, M. (2015), “Measuring performance in a modern police organisation", New perspectives in policing, Harvard Kennedy School and National Institute of Justice.

Stanko, B. (2012). Embedding evidence-based policing in the MPS: The Met leading the way. Unpublished internal document: Metropolitan Police Service.

Willis, J., Mastrofski, S., Weisburd, D. (2007), «Making sense of Compstat. A theory-based analysis of organizational change in 3 police departments », Law $\mathcal{E}$ Society Review, 41(1): 147-188.

Willis, J., Mastrofski, S., Kochel, T. (2010), 'The co-implementation of Compstat and community policing', Journal of Criminal Justice, 38: 969-980. 